DOI: 10.11606/issn.1676-6288.prolam.2016.109573

\title{
OLLANTA HUMALA Y EL CHAVISMO EN LAS ELECCIONES PERUANAS DE 2006
}

\author{
OLLANTA HUMALA AND THE CHAVISM IN 2006 PERUVIAN \\ ELECTIONS.
}

\author{
Ángel Dámaso Luis Leon ${ }^{1}$ \\ Universidad de la Laguna, Tenerife, Islas Canarias, España
}

Resumen: En el año 2006, el Perú se enfrentaba a un proceso electoral que renovaría la cabeza de sus poderes ejecutivo y legislativo. En dichas elecciones y como era habitual en el país, aparecieron personajes externos a los partidos tradicionales que, con su carisma como principal arma, optaron a ganar las mismas. Entre este grupo de habituales contendientes destacó el militar y nacionalista Ollanta Humala. Humala encarnó en el país la ola de ascenso de los movimientos de nueva izquierda populista que habían comenzado en 1999 con la llegada al poder de Chávez en Venezuela. Identificado como elemento de ruptura, en este artículo se busca analizar el conflicto discursivo existente entre los partidarios del cambio bolivariano y las resistencias.

Palabras clave: Ollanta Humala; Perú; Chávez.

\begin{abstract}
In 2006, Peru faces an electoral process that would renew the head of their executive and legislative powers. In these elections, appeared external figures who want to win with his charisma as his main weapon. Among this group of regular contenders highlighted the military and nationalist Ollanta Humala. Humala represented in Peru the rise of the new left populist movements that had begun in 1999 with the arrival to power of Chavez in Venezuela. Identified as an element of rupturein this paper attempts to analyze the existing discursive conflict between supporters of the Bolivarian change and resistance.
\end{abstract}

Key words: Ollanta Humala; Peru; Chávez; elections.

\footnotetext{
${ }^{1}$ Politólogo, investigador de la Universidad de la Laguna. <angelluisleon@gmail.com>.
} 


\section{INTRODUCCIÓN}

El 9 de abril del año 2006 más de 16 millones de peruanos fueron llamados a las urnas para renovar tanto la presidencia de la nación como los representantes al legislativo (y al Parlamento Andino). Estos comicios, además de la importancia intrínseca que poseían, tenían también la particularidad de ser los primeros de cambio democrático tras la caída del fujimorismo en el año 2000. Perú enfrentaba así poco a poco la vuelta a la normalidad democrática tras el impasse de los convulsos años noventa.

Los problemas económicos, sociales, políticos e institucionales que había sufrido el país durante los últimos años de la década de los noventa parecían tocar a su fin con la estabilidad, por lo menos económica e institucional, otorgada por el gobierno del presidente Alejandro Toledo. La mayor prueba de este proceso de retorno era el acatamiento de las normas constitucionales por el propio Toledo, ya que el líder de centro-derecha debía dejar su cargo en 2006 y no podía optar a la reelección por imperativo legal, debido a que en el país andino ésta no estaba permitida de manera inmediata por la modificación que en el año 2000 sufrió la Constitución.

En este ambiente de recuperación de la normalidad se aproximaron unos comicios que presentaban la tendencia política que se ha convertido en habitual en las elecciones peruanas del siglo XXI, es decir, la aparición con una fortaleza, cuanto menos relativa, de individuos con un grado de carisma notable compitiendo frente a otros líderes que proceden de un entorno partidista más tradicional. En el caso de las elecciones de 2006 este individuo con la potencia suficiente como para cuestionar el poder de unos partidos que sí poseían una fuerza previa había sido el militar Ollanta Humala. Si bien Humala representaba un proyecto renovador no era el primero en presentar una candidatura personalista, el presidente Alejandro Toledo también había hecho lo mismo cinco años antes, aunque con una candidatura de corte moderado.

Surgido en el medio, en un sentido ideológico, de las dos tendencias principales del partidismo tradicional peruano, Toledo había conseguido auparse a la presidencia de la nación. El caso de Humala era bien distinto, simpatizante algún tiempo atrás del etnocacerismo, ${ }^{2}$ su crecimiento no se había producido por el centro del espectro político sino que se escoraba bastante hacia la izquierda nacionalista.

El surgimiento y, sobre todo, el fortalecimiento como candidato creíble a la victoria es imposible de concebir sin entender el entorno regional existente en la América Latina de principios del siglo XXI. La ola izquierdista y nacionalista que triunfaba en la práctica totalidad del subcontinente generó ecos en el país andino y la candidatura de Humala encarnó su cristalización política.

En este artículo lo que se plantea es el análisis de la candidatura de Ollanta Humala y su coalición electoral para el año 2006 y cómo incide en sus posibilidades las relaciones personales y programáticas que éste posee con el bolivarianismo en auge en

\footnotetext{
${ }^{2}$ El etnocacerismo es una doctrina política peruana de corte militarista, nacionalista incaica y con rasgos fascistoides que busca la reivindicación de la raza indígena americana. Entre los grandes líderes del etnocacerismo destacan Isaac y Antauro Humala, padre y hermano de Ollanta Humala.
} 
el subcontinente. A su vez, también se busca estudiar el papel desempeñado por sus adversarios en la contienda electoral, y como éstos utilizan el miedo a una deriva bolivariana para convencer al electorado más moderado.

La idea de la expansión del "manto bolivariano" sobre el Perú (con sus particularidades propias como en otros casos) y cómo modifica no solo las relaciones políticas internas, sino también la concepción del proceso electoral en el que el país se encuentra inmerso son, unido a los elementos de la comunicación política, los objetivos de este artículo. Entender, más allá del juego de poder del tablero regional, cómo se desenvuelven los actores en esta nueva situación que se plantea en el Perú.

\section{LA REALIDAD PERUANA Y LOS CONTENDIENTES}

El Perú del año 2005 era un país en pleno proceso de estabilización económica social, institucional y política. Sin embargo, su articulación territoral interna, no demasiado cohesionada, generaba no solo amplias desigualdades entre diferentes zonas de la geografía nacional, sino también conflictos internos.

En el plano económico, Perú se encontraba en una fase de estabilización tras el nefasto segundo lustro de la década de los noventa. El país había salido de la recesión de finales de siglo y su Producto Interior Bruto creció a una media del 4,3\% anual entre los años 2001 y 2005, mientras que el PIB per cápita lo hizo a una media del 3\% para el mismo período. Además de ello, la tasa de inflación se mantenía realmente baja y los indicadores de la deuda externa se habían ido reduciendo lentamente, suponiendo en el año 2005 un 42,3\% de la RNB. A pesar de todo ésto, la gran asignatura pendiente eran los altos niveles de pobreza que experimentaba el país andino y que durante los primeros años del siglo XXI se habían mantenido inalterables, así como una tasa de paro que llegó a rondar el 10\% de la población activa. Se puede decir que la economía había mejorado bastante debido a la estabilización política y a un repunte de los precios de los commodities pero que esta mejora aún no había permeado a la totalidad de los hogares peruanos debido en gran parte al endémico extractivismo capturador de rentas y a la alta informalidad en el empleo que mantenía el país.

Como es lógico, la situación económica de la mitad de los peruanos y la desigualdad existente generaban desafección hacia el sistema. Según el Latinobarómetro de 2005 , el $66,9 \%$ de los peruanos consideraba que sus padres habían vivido mejor que ellos, el 40,9\% de los peruanos consideraba que la democracia no solucionaba sus problemas y hasta un 78,6\% de los mismos se encontraba poco o nada satisfecho con el funcionamiento de la misma en el país. La desconexión de un sector importante del país de un funcionamiento democrático que sentían como ajeno y poco satisfactorio era palpable.

Las políticas liberales de un Toledo que no engañó a nadie con su rumbo dieron sus frutos a nivel macroeconómico, el país estabilizó su crecimiento y la inflación se quedó bajo mínimos, pero el paro y la pobreza quedaron demasiado altos. Esta situación social generó que el gobierno de Toledo llegara a unas cotas de aprobación ciudadana paupérrimas (10\%). El presidente centroderechista había conseguido en las legislativas 
más del $37 \%$ de los curules al Congreso, pero ni siquiera su acercamiento al Frente Independiente Moralizador (FIM) posibilitó la mayoría. Dicha situación de minoría legislativa complicó bastante su gobierno, encontrando una fuerte oposición en el aprismo y por parte de la bancada multipartido conocida como Unión Parlamentaria Descentralista (VELA; RUIZ; GARCÍA y ROCA, 2014, p.113-114). La baja popularidad del presidente y las dificultades del día a día generaron que la llegada de los comicios fueran celebrados por necesarios.

La baja valoración del presidente Toledo influyó en que la carrera presidencial comenzara casi un año antes de los comicios, apareciendo encuestas desde los meses finales del año 2005 que auguraban un fortalecimiento de los partidos tradicionales. En la política peruana de las últimas décadas han existido movimientos ligados a liderazgos carismáticos que han aparecido y desaparecido puntualmente o han quedado en posiciones secundarias, ligados en parte a su sistema de elección (NOHLEN, 2004, pp. 358-369), pero sí que es cierto que, con vaivenes, han sobrevivido cuatro elementos importantes: el aprismo, la democracia cristiana y, en menor medida, el fujimorismo y un diseminado centroderecha.

Entre los actores menores, el centroderecha quedó desolado por el escaso apoyo existente a la gestión del presidente Toledo y su organización política, Perú Posible, se presentaba como mera comparsa a los comicios. Por otra parte, el fujimorismo presentó a una Martha Chávez como candidata que recibiría el apoyo de los nostálgicos del orden y el autoritarismo, pero que tampoco sería un apoyo importante a nivel cuantitativo.

Los grandes bloques tradicionales eran los llamados a ocupar de nuevo las principales esferas de poder a nivel nacional. El aprismo o Partido Aprista Peruano era la principal fuerza partidista del país. Fundado en la década de los 20 por Haya de la Torre como un partido netamente de izquierdas ha ido estableciendo durante las últimas décadas del siglo XX un viraje hacia posiciones más de centroizquierda y perdiendo su carácter radical (MARTÍ PUIG y SANTIUSTE CUÉ, 2006, p. 316-318 y 338). Con un liderazgo fuerte personificado primero en la figura de Haya de la Torre y después en la de Alan García, presidente durante los años de 1985 y 1990 y candidato para 2006, no partían desde la posición de favoritos para dichos comicios. Su principal valor era su poder regional y sus cuadros intermedios. En el año 2001, en las primeras elecciones regionales del post fujimorato, el aprismo había conseguido presentar lista en 23 de las 25 regiones del Perú, obteniendo representantes en el $87 \%$ de las mismas, siendo todo un logro debido al complejo sistema electoral regional. El aprismo consiguió la victoria en el $48 \%$ de los estados del país y se convirtió en primera fuerza a nivel regional, cosechando una media de votos por región del 22,8\%, superando el 50\% en La Libertad o rondando el $30 \%$ en Lima, Ica, Lambayeque, Tacna o Piura. Una barbaridad si se sitúa dentro del contexto de atomización de algunos sistemas regionales peruanos donde no es extraña la existencia de hasta cinco partidos con más del $10 \%$ de voto válido.

La democracia cristiana más que un desarrollo homogéneo en todo el país, cosa que no les faltaba, tenía dos factores a su favor: una larga historia política y de gestión que se remontaba a mediados del siglo XX (SCHMIDT, 2003, pp. 434-468) y una candidata conocida y valorada: Lourdes Flores Nano, la principal favorita durante el año 2005 a la victoria electoral. 
Si bien es cierto que los partidos tradicionales se sentían fuertes, en Perú también existe cierta "tradición" de aparición de elementos externos al sistema que a última hora se muestran competitivos y con posibilidades de victoria. Fujimori fue uno de ellos en su día y Toledo otro. Ese lugar estaba llamado a ser ocupado por el otrora democristiano Valentín Paniagua, pero su candidatura se desinfló muy rápido, aunque ello no fue óbice para que el sistema peruano experimentara un proceso que venía haciéndose fuerte en América Latina: el ascenso de un líder de izquierda populista.

\section{LA FIGURA DE HUMALA Y EL CONTEXTO LATINOAMERICANO}

Ollanta Moisés Humala Tasso (1952- ) llegaba a las elecciones de 2006 con 42 años de edad tras servir durante varias décadas en el ejército. Hijo de una familia de clase media limeña y con aspiraciones políticas, Ollanta había ingresado en el ejército peruano de manera temprana y en él había desarrollado su carrera profesional.

Las similitudes con Hugo Chávez ya eran de origen, puesto que ambos habían desarrollado con honores la carrera militar. Además de ello, ambos habían orquestado sendos levantamientos fallidos contra gobiernos vigentes en sus países. Si bien ello es cierto, la naturaleza de ambos levantamientos es totalmente adversa, Ollanta Humala se levantó el 29 de octubre del año 2000 contra los abusos de poder y el autoritarismo fujimorista, mientras que el golpe de Estado perpetrado por Chávez en el año 1992 había sido en contra de la legalidad democrática (LUIS LEÓN, 2015, p. 93-110). A pesar de ello, su participación le hizo ganarse cierta fama de antisistema. Esa posición de outsider del sistema tradicional de partidos encajaría a la perfección dentro del esquema político del país, que siempre presentaba alternativas externas competentes.

Humala no tenía una organización política medianamente sólida. Como su partido, el Partido Nacionalista Peruano (PNP), no pudo cumplir a tiempo los requisitos legales para competir, Ollanta Humala hizo una alianza electoral con el pequeño partido Unión Por el Perú (UPP) que si contaba con la inscripción legal, y de esta manera pudo ser candidato presidencial (PANFICHI, 2007, p. 02). La candidatura de Humala cabe dentro de un fuerte nacionalismo ${ }^{3}$ heredero en cierta forma del etnocacerismo del que bebió junto a su hermano Antauro. Situado en la izquierda profunda, sus planteamientos económicos iban en una sintonía antiliberal. Se mantuvo en la postura del rol estatal en la economía, el rechazo al Tratado de Libre Comercio (TLC) con Estados Unidos, y a favor a la estatización de los recursos energéticos, aunque moderó el discurso que mantuvo durante sus años de juventud (NESBET-MONTECINOS, 2011, p. 85-86). En el plano político no dudó en proponer un blindaje legal para el estado como actor económico, ni en atacar el modelo institucional y proponer una Asamblea Constituyente que reformulara la construcción de un nuevo país.

A pesar de que hay autores que defienden lo contrario, al igual que Cameron (2007, p. 01), en este artículo se considera a Humala un outsider político: éste era su

\footnotetext{
${ }^{3}$ Fragmento de entrevista de César Hildebrandt al candidato presidencial Ollanta Humala en cadena nacional durante el mes de febrero de 2006, "Hildebrandt entrevista a Humala", en YouTube. Disponible en: https://www.youtube.com/watch?v=O5IW2UzU4Ok (Consultado el 23-11-2015).
} 
mayor activo, y su limitación más importante. Como outsider desafió el sistema de partidos mediante la crítica a los partidos políticos establecidos, presentándolos como élites egoístas, y autoafirmándose, por el contrario, como alternativa no partidista, libre de asociación con la corrupción y la intriga endémica dentro de las instituciones públicas del país. Apelaba a los votantes descontentos y desorganizados que carecen de fuertes vínculos partidistas, así como a los estratos más pobres del sistema y hacía énfasis en su vinculación indígena, ya que buscaba ganar su apoyo.

El proyecto Humala de 2006 era un proyecto populista de izquierdas, entendido el populismo en este caso como un estilo discursivo (GIDRON y BONIKOWSKI, 2013, p. 7-10). Humala establecía una distinción entre la "nación peruana", un concepto que le costaba definir con claridad y que era la representación de todos los valores positivos humanos. En contra de esta nación peruana plagada de virtudes presentaba una amalgama de personajes negativos que simbolizaban todos los antivalores sociales posibles. Esos personajes malignos se anteponían ante la voluntad de la ínclita y pura nación, porque principalmente Humala era eso: un nacionalista.

La competitividad del proyecto humalista es inexplicable sin el auge experimentado por las alternativas de izquierda populista en algunos países latinoamericanos. Los nefastos años noventa y el predominio de las tesis neoliberales llevaron a los electorados de muchos países de la región a optar por soluciones drásticas y elevar al poder a presidentes de corte populista. Aunque algunas veces los medios han tendido a igualar erróneamente fenómenos de izquierda más tradicional (PT en Brasil, Frente Amplio en Uruguay) con la izquierda de corte populista (chavismo en Venezuela, Alianza PAÍS en Ecuador, MAS en Bolivia) ello no limita el hecho de que se haya producido más que una ola populista en América Latina, un efecto contagio desde unos países a otros.

Este proceso de crecimiento y consolidación de este tipo de alternativas comenzó con la victoria del chavismo en Venezuela (1998) y se extendió más tarde a otros países como Bolivia, con la victoria de Evo Morales en el año 2005 y a Ecuador en 2006 con el triunfo presidencial de Rafael Correa. Dicho crecimiento de este tipo de soluciones políticas encontraron amparo en el auge del precio de los commodities, experimentado desde mediados de la primera década del siglo XXI y que permitió llevar a cabo una política redistributiva amplia, ligada a las rentas extraídas de sus suelos y subsuelos. Este tipo de experiencias solidificaron lazos internacionales con otro tipo de proyectos políticos de izquierda radical como el castrismo cubano y el sandinismo nicaragüense y que fueron posibles gracias a la irrigación de las mismas con el petróleo venezolano (BENZI y ZAPATA MAFLA, 2014, pp. 73-76) y que resultaron llamativas para otros países de la región.

\section{LA PRIMERA VUELTA}

El domingo 9 de abril de 2006 más de dieciséis millones de peruanos estaban llamados a urnas para renovar sus principales instituciones de gobierno por primera vez desde el fin del fujimorismo. En este domingo de abril se concentraban las elecciones a tres estructuras gubernativas: el ejecutivo, a través de la elección del Presidente y 
Vicepresidente de la nación; el legislativo, con la elección de los 120 congresistas de la República; y el regional, con los 5 parlamentarios andinos en liza. A pesar de que ese día era la clave, la contienda por el poder había comenzado casi medio año antes.

A finales del año 2015 ya había comenzado la carrera por el bastón presidencial en el Perú. La mayoría de los sondeos de opinión publicados en los dos últimos meses de ese año presentaban un escenario bastante diseminado con mezcla de actores nuevos y conocidos. La mayoría de estos sondeos situaban en cabeza y con una distancia cómoda sobre sus perseguidores (4-12 puntos porcentuales) a la democristiana Lourdes Flores, pero sin opciones de una victoria en primera vuelta. Por detrás de Flores aparecían tres actores que prometían guerra, el aprista Alan García, el nacionalista Ollanta Humala y el conservador Valentín Paniagua con un triple empate con alrededor del $15 \%$ en intención de voto, pero con una diferencia clara: García se estabilizaba, Paniagua se hundía poco a poco, pero Humala crecía a grandes pasos en cada nuevo sondeo publicado.

Hasta ya entrado 2006 no se veía a Humala como un candidato fuerte a la presidencia y por ello el nivel de las críticas que recibía aun era relativamente bajo. A medida que el año avanzaba y éste se hacía fuerte en las encuestas de intención de voto, su figura y programa sufrieron un aumento de las referencias por parte del periodismo y de otros líderes. Es en ese momento cuando comienza la estrategia que acompañará a algunos contendientes y agentes externos durante gran parte de la campaña electoral: la campaña del voto del miedo.

El voto del miedo es el acto de sufragar por parte del elector, compelido o motivado por una serie de temores, amenazas, intimidaciones e incertidumbres sobre el presente y el futuro de una determinada colectividad. Este tipo de voto, se genera por inducción, principalmente por los partidos y candidatos que buscan ganar o conservar una posición de poder político, creando a través de diferentes estrategias de comunicación política, una seria de dudas sobre posibles escenarios futuros adversos y dañinos para la sociedad en el caso de que su opositor, en este caso Humala, gane las elecciones. Las campañas centradas en este tipo de estrategias, buscan principalmente generar temor, cuestionar certezas, crear sospechas y producir dudas respecto de los adversarios (VALDÉZ ZEPEDA y HUERTA FRANCO, 2011, pp. 12-13).

Entre los contendientes que competían con Humala en dichos comicios destacaban la democristiana Lourdes Flores y el aprista Alan García, ya que Paniagua había perdido fuelle con los meses y Martha Chávez se conformaba con mantener la marca fujimorista viva tras el huracán sufrido durante los primeros años del siglo XXI.

Lourdes Flores se había destacado por ser la candidata con la campaña en principio más limpia en la confrontación, ya que no buscaba el intercambio directo con sus adversarios (PUÉMAPE, 2014, pp. 173-174). Propositiva, se presentaba como la continuación sensata que necesitaba el país, reconociendo incluso en alguna entrevista el buen hacer del Presidente Toledo. Aunque sus adversarios la habían nombrado como "candidata de los ricos", la campaña de Flores consistió principalmente en una gira constante por las entidades rurales del Perú, intentando cazar un voto pobre que le era muy esquivo. Con una campaña hiperpersonalizada (CAMERON, 2009, pp. 279-280) y con el respaldo de gran parte de los medios de comunicación (MASÍAS NÚÑEZ y 
SEGURA ESCOBAR, 2006, p. 100), se presentaba en actitud maternal y exponía como uno de sus principales valores el hecho de ser la primera mujer que podría llegar a ser presidenta de la nación.

Durante los primeros meses y con las encuestas de cara, Lourdes Flores se había mostrado moderada con sus adversarios y muy pulcra en sus intervenciones, pero a medida que se fue acercando la fecha de los comicios y su popularidad comenzó a bajar, sacó su parte más ofensiva. Si bien García también recibió sus críticas, fue Humala, objeto de este trabajo, quien más vio aumentada su cuota de ataques. Flores en principio le tildó de ser el candidato del retroceso, del pasado, de tener un proyecto improvisado, para más tarde utilizar expresiones más duras como autoritario o hacer referencias a que una victoria de Humala generaría que el país "termine siendo dominado por la mafia, por un movimiento internacional que aspira a copar la presidencia del Perú", en clara referencia al chavismo y a su líder. Pero no sólo ella, también su candidato a la vicepresidencia, el ingeniero piurano Arturo Woodman, lanzó sus críticas sobre Humala diciendo que "el programa de Humala es copia de lo que hizo Velasco o Chávez, que solo producen pobreza, [...] desconcierto, miedo y atraso".

Pero si alguien fue duro con el candidato nacionalista ese fue el por entonces expresidente Alan García. El aprista partía de una situación de desventaja en las encuestas con respecto a los otros dos candidatos principales a la victoria y por ello buscó la confrontación y la agresividad, apoyándose en su habilidad para la retórica. García buscaba arañar los votos suficientes que le permitieran pasar al balotaje, para ello atacó a Lourdes Flores por el centro para quedarse con el electorado reformista, pero sobre todo intentó ganarse el voto de la izquierda más moderada que no se encontraba del todo cómoda con el radicalismo de Ollanta Humala.

García mantuvo durante toda la campaña a la primera vuelta que Humala "sería un grave tropiezo para el Perú [ya que] haría retroceder el desarrollo, la inversión y el empleo". El aprista cuestionaba continuamente el carácter democrático de la candidatura nacionalista, de la cual afirmaba que tenía "connotaciones evidentemente dictatoriales" y de Humala decía que había "que enseñarle modales democráticos". Su estrategia a la hora de ligar a Humala y el chavismo en esta primera vuelta fue bastante inteligente ya que más que utilizar soflamas en contra del vínculo, lo daba como probado y en algunas ocasiones denominaba a Ollanta como "el protegido de Chávez".

La realidad es que este vínculo Humala-Chávez argüido por García, lejos de ser una artimañana de los que tenían miedo de la propuesta nacionalista-populista del limeño, era una realidad contrastada. No sólo sus discursos e ideología tenían bastantes similitudes, sino que su vinculación no era escondida en un primer momento por el propio Humala. El candidato nacionalista había visitado en enero de 2006 al propio Chávez en Caracas, ${ }^{4}$ donde no sólo habría recibido su bendición y apoyo intelectual, sino también circularon informaciones de que, presuntamente, se habría ofrecido ayuda económica para financiar la campaña electoral. Este contacto poseía un valor formal, pero también tiene un innegable poder simbólico, ya que a su vez que Chávez había recibido la "bendición" de Fidel Castro en 1994, en la Universidad de La Habana,

\footnotetext{
4 “Ollanta Humala en Caracas”, en VTV (Venezolana de Televisión), Caracas, vía YouTube, 03/01/2006. Disponible en: https://www.youtube.com/watch?v=_d6dEpzBdKQ (Consultado el 04-01-2016)
} 
(LUIS LEÓN, 2015, pp. 162-165) Humala la recibía a su vez del que se había convertido en nuevo líder de la izquierda revolucionaria latinoamericana.

Aunque el cruce de declaraciones entre candidatos siempre es algo que se puede esperar en tiempo de elecciones, la confrontación sobrepasó los límites de las candidaturas llegando a otras posiciones. El caso más llamativo fue el conflicto que enfrentó al por entonces presidente Alejandro Toledo con Hugo Chávez. Chávez hizo unas declaraciones sobre los comicios en Perú, identificando a Lourdes Flores como la candidata de la oligarquía, actitud que Toledo se tomó como una injerencia en el país, lo que condujo a una escalada de declaraciones cruzadas entre altos cargos de ambos gobiernos. La realidad es que el conflicto venía de más atrás, ya que las relaciones entre ambos países habían sido bastante frías durante el tiempo en el que Toledo y Chávez fueron los principales mandatarios de sus correspondientes países.

También la prensa jugó un papel esencial en dicha confrontación, ya que si bien su aparición en ésta fue un hecho crucial sin la que es imposible concebir el ascenso de Humala (MÄCKELMANN, 2006, pp. 22-24). Las actitudes de los periódicos hacia su candidatura no fueron las más benevolentes. En los diarios peruanos la actitud era de rechazo o, como mínimo de cierta cautela. Entre los mismos destacaron en agresividad El Comercio y sobre todo El Correo, diario que no dudó en tildar a Humala de fascista, de autoritario (VELA ALTAMIRANO, 2006, pp. 03-04 y 08) o ligarlo a la figura de Hugo Chávez. Pero más allá de las fronteras peruanas también algunos diarios de corte moderado como el estadounidense New York Times o el español El País, también analizaron la candidatura humalista centrándose en el resurgir de la izquierda populista latinoamericana en clave de extensión chavista por el continente.

Finalmente, el 9 de abril, más de 14 millones y medio de peruanos acudieron a las urnas para elegir no solo a su presidente, sino a los curules de su Asamblea Nacional con un saldo que dejó lugar para ciertas sorpresas. Humala ganó la primera vuelta con el $30,6 \%$ de los sufragios válidos por delante de un Alan García que con el 24,3\% de los sufragios, sorpresivamente adelantó a la conservadora Lourdes Flores $(23,8 \%)$. En cuarto lugar, la fujimorista Martha Chávez logró cosechar un 7,4\%, mientras que el democristiano Valentín Paniagua logró un 5,8\%, a la postre decisivo a la hora de configurar que dos candidatos pasaban al balotaje.

Por otra parte, en el legislativo se observó la institucionalización del aprismo, el cual logró ser segundo con 36 escaños y 2,2 millones de votos, pero acercándose la Unión por el Perú de Humala, la cual cosechó 9 escaños más surgidos de conseguir 61.000 votantes más que éstos. En tercer lugar, la campaña personalista de la conservadora Lourdes Flores le permitió ser competitiva pero hundió a su partido en la tercera posición con 17 escaños (1,6 millones de votos), por delante de la fujimorista Alianza por el Futuro (13 escaños, 1,4 millones de votos), del Frente de Centro (5 escaños), Perú Posible y Restauración Nacional (2 escaños cada grupo).

Estos resultados basados en el apoyo personal a Humala estuvieron por encima del promedio en las regiones surandinas, donde se encuentra la mayoría de la población de origen indígena y de mayores niveles de pobreza (TANAKA y VERA, 2007, pp. 237-238). 


\section{ENTRE EL CAMBIO Y LA CONTINUIDAD. EL BALOTAJE}

Alan García había conseguido llegar al punto deseado, el balotaje. El líder aprista sabía que polarizando el debate contra el posicionamiento ideológico y formal de Humala conseguiría atraer el voto miedoso del centro, el centro-derecha y los votantes de Flores y Paniagua. En cierta medida, el votante aprista era más "revolucionario" y podía estar más abierto en una segunda vuelta que en una confrontación directa izquierda-derecha, pero el radicalismo de Humala hacía que el voto conservador de las zonas ricas, y sobre todo, el voto limeño, era muy difícil que se le escapara.

A pesar de encontrarse en auge el populismo de izquierdas en América Latina, la imagen de Chávez en el Perú no era nada buena. Según el Latinobarómetro del año 2006, la imagen que tenían los peruanos de Chávez no llegaba al $3(2,97)$ en una escala de 0 a 10, mientras que la del también bolivariano Evo Morales solamente era un poco mejor $(3,94)$. Si bien estos datos pueden ser más consecuencia que causa de la campaña debido a que fueron recogidos en octubre de ese mismo año, no se puede obviar el miedo que la oleada bolivariana generaba en ciertos grupos sociales peruanos $\mathrm{y}$, principalmente limeños. Además de ello, la nacionalización de los hidrocarburos por parte de Evo Morales en Bolivia durante esos días, aunque pudo gustar a los sectores más nacionalistas, también generó miedos en los más moderados sectores medios.

El propio Alan García no dudó en presentarse en esta campaña por la segunda vuelta como el mal menor para los sectores conservadores ante toda aquella amenaza que suponía Humala para la estabilidad económica del Perú. Alan García, cuya campaña electoral se basó en una especie de expurgo de sus pecados pretéritos, no dudó en expresar lo que, por otra parte, era una realidad, su candidatura se encontraba mucho más cerca del votante mediano (CONGLETON, 2002) que la de Humala. Además de ello y para aumentar la confianza en su persona, no dudó en pedir perdón en varias ocasiones por los errores que había cometido en su primera designación como presidente, así como declarar que había madurado y aprendido de los mismos.

Una vez confirmada la pareja de candidatos para contender a la Presidencia comenzó el fuego cruzado. Humala intentaría venderse como una alternativa no tan radical como se había mostrado en la primera vuelta, posibilitando acceder al voto que le era esquivo y García incidiría en la idea clave de la campaña: Humala era un bolivariano autoritarista sin demasiado cariño por la democracia. García buscó en sus intervenciones un frente de demócratas contra el militarismo y el autoristarismo de cuño bolivariano que representaba Humala. En el mismo debate presidencial del 21 de mayo el propio García, aunque se mostró bastante más comedido que en el resto de la campaña, realizó varias menciones al autoritarismo de Chávez y a otros líderes del "eje bolivariano". 5 Un debate que ganó por goleada debido a su oratoria y porque combinó con exactitud propuestas y ataques a su contrincante.

La campaña por la segunda vuelta fue una batalla que, más allá del posicionamiento formal de varios medios de comunicación en contra del candidato

5 Audios del debate presidencial Humala-García celebrado en el Museo Nacional de Arqueología, Antropología e Historia del Perú, Lima, 21/05/2006. Disponible en: https://es.wikipedia.org/wiki/Debate_Garc\%C3\%ADa-Humala\#Audios_del_Debatev (Consultado el 1812-2015). 
nacionalista (VELA ALTAMIRANO, 2006, pp. 04-09), Alan García jugó magistralmente. El aprista, lejos de buscar el intercambio con Humala, que lo hubo, centró su campaña en la confrontación con el propio Chávez. García sabía que el líder venezolano rara vez rehuye de una confrontación dialéctica y buscó dicha confrontación. El candidato aprista posicionó su discurso en una guerra con Chávez que daba a entender que éste era el que realmente manejaba los hilos de la candidatura de Humala. García llegó a tildar al mandatario venezolano de dictador, llamándolo "Sadam Husseín caribeño" y poniendo en duda el nacionalismo de Humala si se dejaba influenciar tanto por "un padrino que se toma un licor de más, que insulta a todos y que no tiene límites", planteando escoger entre una candidatura peruana y la de Hugo Chávez.

Chávez no dudó en mantener el grado de beligerancia y atacar a un García con el no tenía demasiadas afinidades, llamándole "sinvergüenza" y "ladrón" y generando una reacción diplomática en el país andino que, a su vez, no quedó sin respuesta.

Esta serie de encontronazos de Alan García con Hugo Chávez no quedaron en agua de borrajas e hicieron saltar a la primera plana de los diarios a diversos actores. Ayudado por un presidente Toledo que apoyó a García, esta situación llegó a generar una escalada de tensión diplomática entre ambos países cuyo punto álgido fue cuando el propio Chávez llegó a insultar a García y a amenazar al Perú con retirar el embajador en caso de que el aprista ganara los comicios.

La escalada de declaraciones entre Chávez y casi todo el establishment político peruano complicó la esperada moderación de Humala y los suyos en la segunda vuelta. A pesar de ello, no tardaron en aparecer las voces que alejaban a Humala de un Chávez al que el propio candidato dio la razón en gran parte de los conflictos pero le recomendó "una manzanilla" para calmarse. Pero no fue el único ni el más agresivo con el líder venezolano, la esposa de Ollanta Humala, Nadine Heredia, llegó a tildar al venezolano de "bocafloja". Mientras que el propio partido, Unión Por el Perú (UPP) consideró que el apoyo de Chávez restaba competitividad en el balotaje. A pesar de que se intentaron establecer distancias con los posicionamientos bolivarianos, principalmente con las recientes actuaciones en materia de hidrocarburos de Evo Morales, Humala nunca renegó del todo por lo menos en campaña de sus vínculos ideológicos y programáticos con el eje bolivariano.

Finalmente, el 4 de junio de 2006 se celebró la segunda vuelta de las presidenciales peruanas en las que acudió a votar un uno por ciento menos de los registrados para la primera vuelta. Como mostraba la mayoría de las encuestas, el aprista Alan García ganó los comicios con un 52,6\% de los votos (6.965.017 sufragios), mientras que el nacionalista Ollanta Humala cosechó el 47,4\% de los votos $(6.270 .080$ sufragios). Si bien es cierto que la victoria para García no contundente, si fue lo suficientemente clara. Los resultados dejaron una clara división sociogeográfica en el país encarnada en las dicotomías ciudad (García)-campo (Humala) y costa (García)sierra (Humala) y que hablaban de la escasa vertebración del país (DURAND y GODARD, 2007, pp. 166-168), lo que mostraba en esencia que el discurso antichavista, en cierta medida había calado. 


\section{CONCLUSIONES}

A modo de conclusiones se puede afirmar que Perú no salió indemne al chavismo durante la primera década del siglo XXI. Las elecciones generales de 2006 reflejaron, en gran medida, la pugna que se jugaba en el tablero latinoamericano entre las alternativas de estabilización democrática y la izquierda populista de influencia chavista.

Para comprender el ascenso de Humala hay que analizar ese contexto de pugna internacional, pero también la existencia en el país andino de un sistema de partidos poco estabilizado que generaba el ascenso de outsiders que, con su carisma o su discurso, podían aglutinar un apoyo importante cuantitativamente. Humala se aprovechó de esa no pertenencia a los grupos políticos clásicos y de un discurso rupturista para poder conectar con el elemento que le permitió ser su gloria y su tumba: el bolivarianismo.

Si bien es cierto que Humala es un outsider no lo es menos que no es el único que se puede presentar a la más alta magistratura del Estado. Luego, ¿qué es lo que le permite a Ollanta Humala tener ese relativo éxito? Sin duda alguna, la bendición de Hugo Chávez. Surgido de un partido que ni siquiera puede presentarse a los comicios y acusado de tener un pasado turbio, es la "bendición" que recibe por parte de Chávez la que le permite salir indemne a ciertos ataques y ganar un porcentaje de votos para nada desdeñable, convirtiéndose en ganador de la primera vuelta.

Pero como se ha mencionado anteriormente, el apoyo chavista es el trampolín de Humala, pero también su tumba. Si bien es cierto que existe un grupo social, mayormente poco afortunado en el reparto social, que anhela una solución "a la venezolana", e incluso hay sectores medios que no repudian el autoritarismo fujimorista y que le apoyan, el apoyo de Chávez es una limitación demasiado fuerte a la hora de girar al centro y poder atacar el amplio sector de voto democristiano y centroderechista. Más allá del escaso apoyo mediático que recibe, en una contienda con García, su acceso al votante mediano (CONGLETON, 2002) era bastante limitado.

Esta limitación del proyecto es observada muy claramente por Alan García que busca atacar por ese flanco, no ya a un Humala que quiere despegarse de Chávez, sabiendo que es una limitación, sino al propio mandatario venezolano para que éste le enfrente y le relance a la opinión pública como su antagonista. García, cuyas posibilidades de victoria pasan por hacer creer al votante urbano, de clase media y alta e ideológicamente moderado aunque escorado a la derecha, genera la idea de que su lucha es contra los tentáculos de la revolución bolivariana que están llegando a Perú. En esa lucha entre gigantes, la figura de Humala queda como la de un espectador participante que se ahoga entre la disyuntiva de renunciar a su voto de base rompiendo buscamente con Chávez o esperar que García no consiga su objetivo y cazar al escaso votante antiestablishment que se encuentra fuera de su redil.

En definitiva, no se puede entender el desarrollo de los comicios de 2006 sin el centro reconfigurador de posiciones que supone Caracas a principios del siglo XXI. El bolivarianismo nacido en Venezuela se comporta, directa o indirectamente, como un renovador de las simpatías y aritméticas existentes en América Latina y, principalmente 
en el área andina. Ya sea con victorias de compañeros ideológicos como en Bolivia (Evo Morales en 2005) o Ecuador (Rafael Correa en 2006) o con derrotas de candidatos competitivos como en México (Andrés Manuel López Obrador en 2006) o en el propio Perú (Ollanta Humala en 2006), la influencia del "modelo venezolano" se extiende por toda Latinoamericana marcando los debates, los discursos y las formas de hacer política en una región que experimenta una década de fulgurante crecimiento y expansión.

\section{BIBLIOGRAFÍA}

\subsection{REVISTAS Y LIBROS}

BENZI, Daniele; ZAPATA MAFLA, Ximena. Petrolio e petrodollari nella politica internazionale de Venezuela. Una breve resegna storica (1958-2012). Jul., n. 11, p. 6380, 2014.

CAMERON, Maxwell A. Peru's Ollanta Humala: The Rise and Limits of a Left-Wing Political Outsider. LASA paper, 2007.

CONGLETON, Roger D. The median voter model. In ROWLEY, Charles; SCHNEIDER, Friedrich (Eds.). The encyclopedia of public choice. Nueva York: Springer US, 2004.

DURAND, Mathieu; GODARD, Henri. Las elecciones presidenciales en el Perú en 2006: un indicador de la segregación socio-espacial y de la protesta social. Bulletin de l'Institut français d'études andines, n. 36 (1), p. 165-170, 2007.

GIDRON, Noam; BONIKOWSKI, Bart. Varieties of populism: Literature review and research agenda. Wheaterhead Center for International Affairs, n. 13-0004, 2013.

LUIS LEÓN, Ángel Dámaso. Chávez al poder. Génesis y formación del movimiento bolivariano. Santa Cruz de Tenerife: Ediciones Idea, 2015.

MÄCKELMAN, Mathias. Perú 2006: comunicación política y elecciones: Bailando, gritando y escuchando. Diálogo Político, v. 23, n. 2, p. 11-34, 2006.

MARTÍ PUIG, Salvador; SANTIUSTE CUÉ, Salvador. La izquierda parlamentaria en América Latina: ¿Nuevas percepciones sobre la democracia y el mercado. In ALCÁNTARA SAEZ, Manuel (Ed.). Políticos y política en América Latina. Madrid: Siglo XXI, Fundación Carolina, 2006.

MASÍAS NÚÑEZ, Rodolfo; GARCÍA ESCOBAR, Federico. Elecciones Perú, 2006: complejidades y paradojas de una democracia vulnerable. Colombia Internacional, $\mathrm{n}$. 64, p. 96-121, jul-dic 2006. 
NESBET-MONTECINOS, Felipe. Humala antes de Ollanta: evolución política del nuevo presidente peruano. Revista Europea de Estudios Latinoamericanos y del Caribe 91, p. 81-90, oct.2011.

NOHLEN, Dieter. Sistemas electorales y partidos políticos. México D.F.: Fondo de Cultura Económica, 2004.

PANFICHI, Aldo. Perú Elecciones 2006: Auge y caída del nacionalismo de Ollanta Humala. (Work Paper), Pontificia Universidad Católica del Perú, 2007.

SCHMIDT, Gregory D. La gran minoría: la democracia cristiana en el Perú. In MAINWARING, Scott; SULLY, Timothy R. La democracia cristiana en América Latina. Conflictos y competencia electoral. Mexico D.F: Fondo de Cultura Económica, 2003.

TANAKA, Martín; VERA, Sofía. Perú: entre los sobresaltos electorales y la agenda pendiente de la exclusión. Revista de Ciencia Política, v.. especial, p. 235-247, 2007.

VELA, Estelí; RUIZ, Gabriela; GARCÍA, Sebastián; ROCA, Pablo. La disciplina y efectividad de las bancadas de oposición en el Parlamento en los casos de interpelaciones durante los gobiernos de Toledo, García y Humala (2001-2013). Politai: Revista de Ciencia Política, Año 5, primer semestre, n. 8, p. 99-128, 2014.

VELA ALTAMIRANO, Juan Carlos. La actuación de los medios y la construcción del escenario político en los diarios: El Comercio, La República, Perú 21 y Correo. Elecciones presidenciales Perú 2006. Centro de Competencia en Comunicación para América Latina, p. 1-32, 2006.

\subsection{RECURSOS LEGALES}

OFICINA NACIONAL DE PROCESOS ELECTORALES (ONPE). Elecciones Congresales 2006, Lima, 2006.

OFICINA NACIONAL DE PROCESOS ELECTORALES (ONPE). Elecciones Presidenciales 2006, Resultados Generales Elecciones Presidenciales, Lima, 2006.

OFICINA NACIONAL DE PROCESOS ELECTORALES (ONPE). Elecciones Regionales y Municipales 2002 y Municipales Complementarias 2003, Lima, 2003.

OFICINA NACIONAL DE PROCESOS ELECTORALES (ONPE). Segunda Elección Presidencial 2006, Lima, 2006. 